\title{
Vitamin D and Covid-19: an update on evidence and potential therapeutic implications
}

\author{
Giuseppe Murdaca ${ }^{{ }^{*}} \mathbb{D}$, Giovanni Pioggia ${ }^{2}$ and Simone Negrini ${ }^{1}$
}

\begin{abstract}
The world is now experiencing its third major epidemic of coronavirus (CoV) infections began in Wuhan, Hubei, China, in late 2019 and named COVID-19. After an initial explosive outbreak of pneumonia of unknown etiology in China, the disease spread first to neighboring Asian countries and then worldwide. Patients with COVID-19 presented with a constellation of symptoms such as fever, dry cough, dyspnea, sore throat, and nasal congestion and radiological findings showed bilateral lung glassy opacities. Vitamin D has many mechanisms by which it reduces the risk of microbial infection and death, including physical barrier, cellular natural immunity, and adaptive immunity. Vitamin D supplementation has shown favorable effects in viral infections including influenza and HIV. The effects of vitamin D supplementation during covid 19 infection remain controversial. Looking ahead, clinical studies are needed to define better cut offs for vitamin D levels and, finally, which dosage is the best.
\end{abstract}

Keywords: Vitamin D, Covid-19

\section{Key points}

- Vitamin D reduces the risk of microbial infection and death.

- Vitamin D supplementation has shown favorable effects in viral infections including influenza and HIV.

- Vitamin D is a negative endocrine renin-angiotensin system (RAS) modulator.

- Vitamin D increases expression and concentration of ACE2, MasR and Ang-(1-7) and has a potential protective role against acute lung injury/acute respiratory distress syndrome.

\footnotetext{
*Correspondence: giuseppe.murdaca@unige.it

${ }^{1}$ Department of Internal Medicine, University of Genoa and IRCCS

Ospedale Policlinico San Martino, Viale Benedetto XV, n. 6, 16132 Genova, Italy

Full list of author information is available at the end of the article
}

- Despite the potential effectiveness of vitamin D as an antiviral, more solid data are needed to support this claim.

\section{Background}

Currently, a major epidemic of coronavirus $(\mathrm{CoV})$ infection is occurring worldwide. The current $\mathrm{CoV}$ infection started in Wuhan, Hubei, China, late in 2019 [1]. On February 11, 2020, the World Health Organization (WHO) named the epidemic COVID-19 [2]. In 2002, the first epidemic of a $\mathrm{CoV}$ infection also began in China, for which the clinical features included severe acute respiratory syndrome (SARS)-CoV [3], while another-currently ongoing in the Middle East-was first reported in 2012 [4] and is named Middle East respiratory syndrome (MERS)-CoV. The epidemic of COVID-19 is the third one which, starting from an explosive outbreak only in China and subsequently in neighboring Asian countries, spread worldwide [5], with several countries including the USA, Italy, Spain, China, Germany and Iran leading

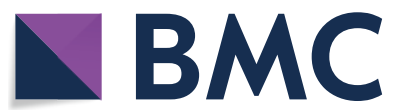

(c) The Author(s) 2020. This article is licensed under a Creative Commons Attribution 4.0 International License, which permits use, sharing, adaptation, distribution and reproduction in any medium or format, as long as you give appropriate credit to the original author(s) and the source, provide a link to the Creative Commons licence, and indicate if changes were made. The images or other third party material in this article are included in the article's Creative Commons licence, unless indicated otherwise in a credit line to the material. If material is not included in the article's Creative Commons licence and your intended use is not permitted by statutory regulation or exceeds the permitted use, you will need to obtain permission directly from the copyright holder. To view a copy of this licence, visit http://creativeco mmons.org/licenses/by/4.0/. The Creative Commons Public Domain Dedication waiver (http://creativecommons.org/publicdomain/ zero/1.0/) applies to the data made available in this article, unless otherwise stated in a credit line to the data. 
in terms of the most confirmed cases and related deaths [6]. Samples gathered from throat and nasal swabs are useful to perform a polymerase chain reaction (PCR) analysis which is able to detect the SARS-CoV-2 infection [7]. The main symptom of COVID-19 is fever (85\% of cases), and in early onset $45 \%$ of cases include febrile, dyspnea, dry cough, sore throat, nasal congestion, and radiological findings showing bilateral lung glassy opacities. Damage to the lung tissue may result in acute respiratory distress syndrome (ARDS), of which a potential consequence is septic shock. These are the two major COVID-19 contributors to hospitalization in an intensive care unit (ICU) and mortality in patients who are more than 60 years old. Several other symptoms, such as bone and muscle aches, chills, and headaches are under observation [7]. Minor reported symptoms include nausea or vomiting and diarrhea, respectively in 5\% and 3.7\% of cases [7]. Furthermore, anosmia and ageusia appear to be frequent clinical features in COVID-19 patients [8]. Several works have reported how the group of subjects who are smokers, especially at an older age, tend to have a higher density of angiotensin converting enzyme 2 (ACE2) receptors [9]. COVID-19 has an incubation period of around 2-14 days, with a mean of 3 days and a fatality rate (CFR) of $12 \%$ worldwide [9]. The suggested cut-off for self-quarantine is 14 days [7]. Subjects with COVID-19 show decreased or normal leucocytes and lymphocytopenia, as well as a systemic elevation of pyrogenic cytokines such as interleukin (IL)-6, IL-10, and tumor necrosis factor (TNF)- $\alpha[7,10]$. When subjects are in a critical condition, several studies have reported an increase of neutrophilia and elevated D-dimer, as well as urea nitrogen (BUN) and creatinine in the blood plasma $[7,10,11]$. Increased plasma levels of IL-2, IL-7, IL-10, granulocyte colony stimulating factor, $10 \mathrm{kD}$, interferon (IFN)- $\gamma$-induced-protein-10, monocyte chemoattractant protein-1, and macrophage inflammatory protein 1- $\alpha$ have also been reported [10]. Early diagnosis, isolation, and treatment are essential to cure the disease and control the epidemic. Serum antibody detection is of great significance in the diagnosis of infected patients, especially for patients with a negative nucleic acid test. Simultaneous detection of both IgM and IgG antibodies helps to identify the stage of the infection. Generally, the antibody profile against COVID-19 shows a typical IgM and IgG pattern profile. SARS-specific IgM antibodies appear about two weeks after infection, and disappear at the end of week 12, while the IgG antibodies may last for months or even many years [12]. For COVID-19, however, the longitudinal pattern of antibodies remains unclear [13]. Presently, a dedicated treatment has not yet been developed, and trials of antiviral drugs remain experimental. Moreover, an official vaccine has not yet been approved; the completion time for such a vaccine is estimated to be by June 2021 [9]. Taking into account the effects of corticosteroids in prolonging the viral shedding time and in maintaining the systemic anti-inflammatory state while minimizing the precipitation of ARDS, dyspnea, and severe pneumonia, several attempts have been made in the management of such pathologies of viral pneumonia to use systemic corticosteroids. However, their application remains controversial. For this reason, the use of corticosteroids is not recommended outside of clinical trials, or unless otherwise indicated [9]. Notably, heparin treatment can contribute to reduced mortality in patients with severe COVID-19 and sepsis-induced coagulopathy [14]. However, chloroquine (CQ) and its hydroxychloroquine derivative (HCQ) have been administered to patients with severe symptoms [15-18]. It has been reported that anesthetics (i.e., propofol) can disrupt ordered monosialotetrahexosylganglioside1 (GM1) lipid rafts. These same lipid rafts recruit the COVID-19 surface ACE2 to an endocytic entry point, away from phosphatidylinositol 4,5 bisphosphate (PIP2) domains [19]. Of note, HCQ acts through anesthetic-like mechanism disrupting ACE2 localization at both GM1 rafts and PIP2 domains decreasing the ability of the virus to cluster and enter the cell [20]. Furthermore, HCQ seems to inhibit important functional proteins for COVID-19 replication, with potency increasing in the series PLpro, 3CLpro, $\operatorname{RdRp}$ [21]. It has been reported that supplements with vitamin $\mathrm{A}, \mathrm{B}, \mathrm{C}, \mathrm{D}$, and $\mathrm{E}$ seems to have a beneficial effects in patients with viral infections as COVID-19 [2, 22-25]. Within such a panorama, it is worth mentioning that vitamin D mitigates the scope of acquired immunity and regenerates the endothelial lining. In this review, we discuss the potential role of vitamin D supplementation in COVID-19 infection.

\section{Vitamin D metabolism}

Due to the thermal action of UVB radiation reaching 7-dehydrocholesterol in the skin, vitamin D3 is produced. Following this reaction, vitamin D3 or oral vitamin D is then converted in the liver to $25(\mathrm{OH}) \mathrm{D}$ and then, in the kidneys or other organs, to the hormonal metabolite 1,25(OH)2D (calcitriol) [26, 27]. Calcitriol enters the nuclear receptor of vitamin D, binding with DNA. This binding allows a direct interaction with the regulatory sequences near target genes, for which chromatin active complexes genetically and epigenetically contribute to modifying the transcriptional output [27]. Calcitriol contributes to regulating the concentrations of serum calcium through a feedback loop with parathyroid hormone $(\mathrm{PTH})$, and in this way modifies many important functions in the body [26]. 


\section{Vitamin $D$ and the host immune response}

Vitamin D contributes to reducing the risk of microbial infection and death, mainly involving actions grouped into three categories: physical barriers, cellular natural immunity, and adaptive immunity [28]. Innate cellular immunity is strengthened by vitamin $\mathrm{D}$ actions partly through the induction of antimicrobial peptides, including the human cathelicidin LL-37 and by 1,25-dihdroxyvitamin D and defensins, while maintaining tight junctions, gap junctions, and adherens junctions [29-32]. In particular, it is worth mentioning the effects of cathelicidins, which exhibit a direct antimicrobial effect versus a wide range of microbes. These include, among others, Gram-positive and Gram-negative bacteria, enveloped and non-enveloped viruses, and fungi [33]. Cathelicidin displays other functions including the induction of a variety of pro-inflammatory cytokines, stimulation of the chemotaxis of neutrophils, monocytes, macrophages, and $\mathrm{T}$ lymphocytes into the site of infection, and promotion of the clearance of respiratory pathogens by inducing apoptosis and autophagy of infected epithelial cells [34, 35]. Furthermore, 1,25(OH)2D-vitamin D receptor complex acts on the cathelicidin gene promoter vitamin $\mathrm{D}$ response elements to enhance transcription of cathelicidin [36]. COVID-19 subjects show innate behaviour of the immune system in response to viral and bacterial infections, generating both pro-inflammatory and anti-inflammatory cytokines [37]. Vitamin D may contribute to reducing the production of pro-inflammatory $\mathrm{T}$ helper (Th) 1 cytokines, (TNF- $\alpha$ and IFN- $\gamma$ ), and increases the expression of anti-inflammatory cytokines by macrophages $[38,39]$. Vitamin D promotes cytokine production by Th2 lymphocytes, enhancing the indirect suppression of Th1 cells by complementing this with actions mediated by a multitude of cell types [40]. It also favors induction of the $\mathrm{T}$ regulatory (Treg) cells, thereby inhibiting inflammatory processes [41, 42]. Serum vitamin D concentrations tend to decrease with age due less time spent in the sun and lower levels of 7-dehydrocholesterol in the skin [43, 44]. Notably, vitamin D concentrations in the serum can be reduced by antiepileptics, antineoplastics, antibiotics, anti-inflammatory agents, antihypertensives, antiretrovirals, endocrine drugs, and some herbal medicines, through the activation of the pregnane-X receptor [45]. The expression of genes related to antioxidation (glutathione reductase and the glutamate-cysteine ligase modifier subunit) is enhanced by supplementation of Vitamin $\mathrm{D}$ [46] and, thus, the increased glutathione production spares the use of vitamin $\mathrm{C}$, which has antimicrobial activities $[47,48]$. The effects of vitamin D on the immune system are shown in Fig. 1.

\section{Vitamin D and COVID-19}

Winter vitamin D supplementation seems to reduce the risk of developing influenza. Two randomized controlled trials (RCTs) have reported beneficial effects along these lines $[49,50]$. A few studies have presented some limitations in the design of these clinical trials; for instance, an RCT in Japan which included many subjects who had been vaccinated against influenza and did not measure baseline vitamin $\mathrm{D}$ levels reported no benefit from the administration of vitamin D [51]. However, the two most recent RCTs included participants with above average mean baseline vitamin D concentrations [52, 53]. Gruber-Bzura et al. [54] reported that vitamin D should reduce the risk of influenza, even if other studies are needed to confirm these findings. Furthermore, the potential beneficial effects of vitamin D supplementation have also been described in human immunodeficiency virus-1 (HIV) infection. Indeed, Mansueto et al. [55] reported that preclinical experiments have demonstrated that treatment of peripheral blood mononuclear cells with $1,25(\mathrm{OH}) 2 \mathrm{D}$ decreased the cell susceptibility to HIV infection by inhibiting viral entry, modulating the expression of CD4+ cell surface antigens, damping viral p24 production, and limiting monocyte proliferation. Baseline vitamin D levels lower than $32 \mathrm{ng} / \mathrm{mL}$ were independently associated with progression to a more advanced HIV stage. These findings seem to confirm the potential benefits of the administration of vitamin D in HIV patients, even if assay variability and costs, lack of a clear target range, absence of proven supplementation benefits, confounding from osteoporosis and older age, limited RCT data in HIV-infected patients, and finally the inability to distinguish the effects of vitamin D prevent routine screening of vitamin $\mathrm{D}$ levels. In terms of the potential impact of vitamin D supplementation in patients with COVID-19 infection, experimental reports have shown vitamin $\mathrm{D}$ has a role in reducing the risk of COVID-19, including consideration of the fact that the outbreak occurred in winter (a time when serum vitamin D levels are lowest), and the fact that vitamin D deficiency contributes to acute respiratory distress syndrome and case-fatality rates increasing with age and with chronic disease comorbidity, both of which are associated with a lower $1,25(\mathrm{OH}) 2 \mathrm{D}$ concentration [2]. However, it is reasonable to hypothesize that vitamin $\mathrm{D}$ supplementation may enhance host immune responses against COVID-19 and its aggressive effects on all organ systems. High-dose vitamin D supplementation may be considered for subjects with laboratory confirmed deficiency, particularly the elderly, obese, those with dark skin, and those individuals living at higher latitudes. Thirty-five degrees North also happens to be the latitude above which people do not receive sufficient sunlight to 


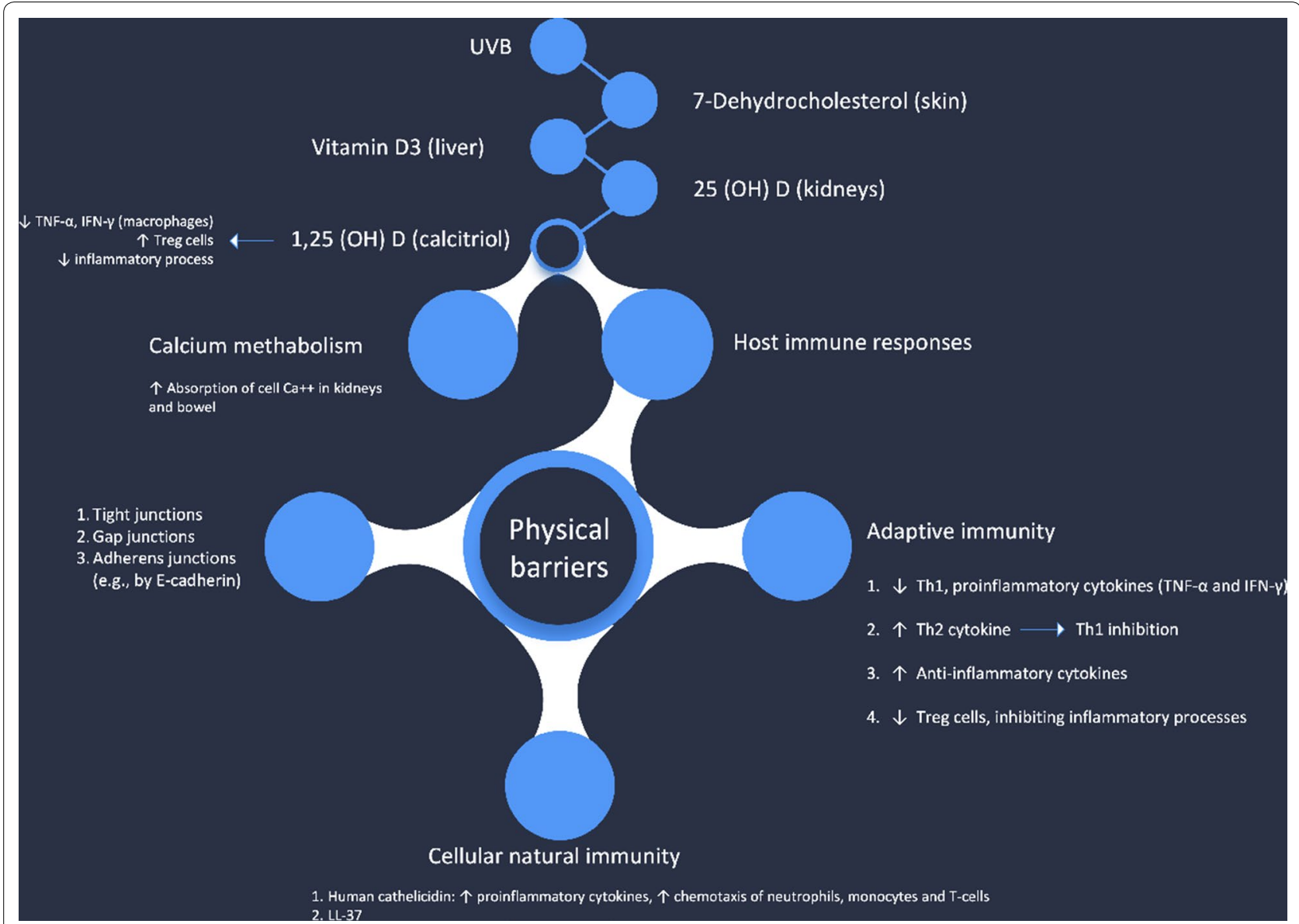

Fig. 1 Effects of vitamin D on immune system, calcium metabolism and cytokines

retain adequate vitamin $\mathrm{D}$ levels during winter and, thus, vitamin D supplementation is needed. Based on its protective effects in subjects at risk of chronic diseases, including cancers, cardiovascular disease (CVD), respiratory tract infections, diabetes mellitus, and hypertension, it can be assumed that vitamin D supplementation and the associated increase of serum vitamin D levels above $50 \mathrm{ng} / \mathrm{ml}(125 \mathrm{nmol} / \mathrm{l})$ may have beneficial effects in reducing the incidence and severity of various viral diseases, including COVID-19 [5, 56]. Given the well-known deleterious consequences of malnutrition [57], and keeping in mind the peculiarities of the ICU setting, Caccialanza et al. [58] planned a pragmatic protocol for early nutritional supplementation of non-ICU patients hospitalized for COVID-19. Almost all COVID-19 hospitalized patients present at admission with severe inflammation and anorexia, leading to a major reduction of food intake, and a substantial percentage of them develop respiratory failure requiring non-invasive ventilation (NIV) or continuous positive air-way pressure (CPAP) within a few days. Furthermore, taking measurements of weight and height may be difficult, mainly due to a lack of scales, as well as in consideration of the required hygienic precautions. Moreover, measurements of body composition may not be regularly gathered during the peak of an epidemic, due to the associated safety concerns. Parenteral nutrition (PN) may only partially fit the needs of subjects with pre-ICU COVID-19, because central infusion lines are rarely available outside ICU wards, and as requirements for energy are likely to be elevated considering the concurrent severe acute inflammatory state and that the average BMI of COVID-19 patients is often high upon admission. Tian et al. [59] confirmed gastrointestinal clinical and laboratory features in COVID-19 from case reports and retrospective clinical studies. As previously reported, ACE2 is the receptor which hosts COVID-19 entry into the cells of the intestine and alveoli, with dysregulation of the renin-angiotensin system which contributes to massive cytokine activation; this can be potentially fatal in ARDS. However, vitamin D deficiency may also contribute to airway/gastrointestinal infections. Of note, elderly 
Italians have a very high prevalence of hypovitaminosis $\mathrm{D}$, with a peak during the winter season [60]. It has been proven that vitamin $\mathrm{D}$ in mice attenuates acute lung injury caused by lipopolysaccharide-induction, by blocking the effects of the angiopoietin (Ang)-2-Tie-2 signaling pathway and on the renin-angiotensin pathway [61]. Furthermore, Malek Mahdavi confirmed that vitamin D is a negative endocrine renin-angiotensin system (RAS) modulator and inhibits renin expression and generation. It can induce ACE2/Ang-(1-7)/MasR axis activity and inhibits renin and the ACE/Ang II/AT1R axis, thereby increasing expression and concentration of ACE2, MasR and Ang-(1-7) and having a potential protective role against acute lung injury/ARDS. Therefore, he suggested that vitamnin $\mathrm{D}$ may be a potential therapeutic approach to combat COVID-19 and induced ARDS [62, 63]. Although it is more likely that any protective effect of vitamin D against COVID-19 is related to suppression of cytokine response, it seems possible that vitamin D prophylaxis (without over-dosing) may decrease the severity of illness caused by COVID-19, especially in settings where hypovitaminosis D is common [64]. Moreover, Marik et al. [65] suggested that hypovitaminosis D may partly explain the geographic variations in the reported case fatality rate of COVID-19, indicating that supplementation with vitamin D may reduce the mortality from this pandemic. These findings confimed that persistent deficiency in vitamin $D$ level may activate the RAS that induces lung fibrosis [65]. Furthermore, hypovitaminosis D promotes the renin-angiotensin system (RAS), chronic activation of which may lead to chronic CVD and decreased lung function [66]. Tsujino et al. [67] recently reported, both in mouse models of bleomycininduced interstitial pneumonia and human cells, that vitamin D3 is activated in lung tissue and this activation shows a preventive effect on experimental interstitial pneumonitis. Martineau et al. [68] confirmed the safety and the protective effect against acute respiratory tract infection of regular oral vitamin D2/D3 intake (up to $2000 \mathrm{IU} / \mathrm{d}$ without an additional bolus), especially in subjects with vitamin D deficiency. Vitamin D supplementation increases the peripheral $\mathrm{CD} 4+\mathrm{T}$ lymphocyte count in HIV infection [69], and one of the main manifestations of severe COVID-19 infection is lymphopenia. Hanff et al. [70] speculated that CVD or RAS blockade drugs might augment ACE2 levels, increasing the available substrate for COVID-19 infection. COVID-19 infection is thought to downregulate ACE2 function, leading to toxic angiotensin II over-accumulation, which in turn may contribute to ARDS or fulminant myocarditis. Notably, hypovitaminosis D seems to increase the risk for thrombosis, and vitamin D controls the expression of several genes relevant to cellular proliferation, differentiation, apoptosis, and angiogenesis [71]. The administration of a high dose of $25(\mathrm{OH})$ vitamin D significantly decrease the need to admit COVID-19 patients to ICU [72]. However, hCAP-18 is the only human cathelicidin hydrolyzed by proteinase 3 between an alanyl and a leucyl residue to produce an antibacterial peptide LL-3 that also inhibits platelet aggregation reducing the risk of thrombus formation. LL-37 can reduce phosphorylation of Src kinase and $\mathrm{Akt}^{\mathrm{Ser} 473}$, decrease platelet spreading on immobilized fibrinogen and inhibit P-selectin expression on platelets [73]. Endothelial cells could be infected by COVID-19 through ACE2 receptors on the endothelium inducing endothelial dysfunction [74]. Induction of endothelial dysfunction may be also relevant to an inadequate degree of $1,25(\mathrm{OH}) 2 \mathrm{D} 3$, which cannot efficiently act as a ligand for vitamin Dreceptor (VDR), resulting in the disorder of vitamin D-binding protein binding to the ligand for VDR on the endothelium. Furthermore, TNF- $\alpha$ increases interferon (IFN)- $\alpha$ inducing secondary endothelial dysfunction and, thus, increasing the risk of endothelialitis, coagulopathy and thrombosis. Vitamin D deficiency makes patients more at risk of death [74]. These findings confirm that hypovitaminosis $\mathrm{D}$ may be associated with an increased risk of severity in COVID-19 and, thus, are further evidence of the positive role played by vitamin $\mathrm{D}$ supplementation in the immune response $[64,75,76]$. Interestingly, Italy and Spain, perhaps contrary to expectation, each have a relatively high prevalence of vitamin $\mathrm{D}$ deficiency [77]. Intensive vitamin D supplementation as a possible prophylaxis could be considered in addition to exposure to UVB rays, as we are still lacking specific and effective treatments for COVID-19. The good tolerability and safety of even of high doses of vitamin D makes vitamin D supplementation consistent with the primum non nocere principle. Investigations on vitamin $\mathrm{D}$ status and VDR gene polymorphisms could explain the unusual behavior of COVID-19's spread, and the variety of clinical presentations and outcomes [78]. Given the link between diminished immune function and individuals with obesity, this raises important questions about the possibility for greater viral pathogenicity in this population [79]. Increased adiposity may undermine the pulmonary microenvironment (e.g., alveoli), wherein viral pathogenesis and immune cell trafficking could contribute to a maladaptive cycle of local inflammation and secondary injury, further worsened by the presence of high blood pressure and diabetes mellitus-both of which are typically connected to obesity $[80,81]$. In patients with type 2 diabetes mellitus hyperinsulinaemia promotes lowers vitamin D status via sequestration into adipocytes decreasing plasma membrane negative charge between red blood cells, platelets and endothelial cells, and, thus, increasing agglutination and thrombosis [82]. Particular 
attention must be dedicated to treatment with testosterone; its safety is under discussion due to recent evidence in patients with COVID-19, in particular in hypogonadal men with a greater genetic predisposition, of an increased frequency of venous thromboembolism (VTE) - a clinical element associated with a worse prognosis [83]. However, the risk of VTE in patients treated with testosterone is very current. In a recent case-crossover study, 39,622 men were enrolled and 3110 of them (7.8\%) had hypogonadism. Testosterone replacement therapy was associated with a higher risk of VTE in men with (odds ratio 2.32) and without (odds ratio 2.02) hypogonadism [84]. What is the link between the male testosterone levels and the risk of severe lung involvement in patients with COVID-19? Based on the role of the variation in androgen levels throughout life [85], testosterone could play a double-edged role in the natural history of COVID-19 infection. In the early phase, the immunosuppressive action of testosterone could explain male's greater susceptibility to infection therefore leading to speculate a protective role of ADT. On the contrary when the infection occurred, in elderly males who frequently develop ARDS, late-onset hypogonadism could result in a lower immunosuppressive effect on the cytokine storm [86]. Indeed, in subjects with hypogonadism, testosterone inhibits the immune stimuli-induced secretion of proinflammatory cytokines, such as TNF- $\alpha$ and IFN- $\gamma$, which can be measured in the peripheral blood leukocytes, demonstrating a worsening of the systemic inflammatory response [83]. These findings further support the hypothesis that vitamin D prevents the cytokine storm and subsequent ARDS that is commonly the cause of mortality in COVID-19 infection [80, 81]. In subjects with HIV infections, a deficiency of vitamin $\mathrm{D}$ is associated with increased levels of IL-6 [87], while in diabetic mice supplementation of vitamin D can reduce excess IL-6 levels [88].

\section{Conclusion and perspectives}

Data reported in the literature concerning the effects of vitamin $\mathrm{D}$ supplementation are yet controversial in patients with COVID-19. The pathology of COVID19 involves a complex interaction between COVID-19 and the immune system. However, vitamin D has multiple immunomodulating actions. Of note, vitamin D favors the ability of macrophages to mature and prevents macrophages from releasing too many inflammatory cytokines and chemokines. Furthermore, Vitamin D supplementation has shown favorable effects in numerous viral infections. However, data still available on the effects of vitamin D supplementation during covid 19 infection remain controversial. Looking ahead, clinical studies are needed to define better cut offs for vitamin D levels and, finally, which dosage is the best.

\section{Acknowledgements}

Not applicable

Authors' contributions

All authors read and approved the final manuscript.

Funding

There is no funding to declare.

Availability of data and materials

Not applicable.

Ethics approval and consent to participate

Not applicable.

Consent for publication

Not applicable.

\section{Competing interests}

The authors declare that they have no competing interests.

\section{Author details}

${ }^{1}$ Department of Internal Medicine, University of Genoa and IRCCS Ospedale Policlinico San Martino, Viale Benedetto XV, n. 6, 16132 Genova, Italy. ${ }^{2}$ Institute for Biomedical Research and Innovation (IRIB), National Research Council of Italy (CNR), 98164 Messina, Italy.

Received: 27 June 2020 Accepted: 11 November 2020

Published online: 19 November 2020

References

1. Zhu N, Zhang D, Wang W, Li X, Yang B, Song J, Zhao X, Huang B, Shi W, Lu $R$, et al. A novel coronavirus from patients with pneumonia in China, 2019. N Engl J Med. 2020;382(8):727-33.

2. Grant WB, Lahore H, McDonnell SL, Baggerly CA, French CB, Aliano JL, Bhattoa HP. Evidence that vitamin D supplementation could reduce risk of influenza and COVID-19 infections and deaths. Nutrients. 2020;12:4

3. Zhong NS, Zheng BJ, Li YM, Poon LLM, Xie ZH, Chan KH, Li PH, Tan SY, Chang Q, Xie JP, et al. Epidemiology and cause of severe acute respiratory syndrome (SARS) in Guangdong, People's Republic of China, in february, 2003. Lancet. 2003;362:1353-8.

4. Assiri A, McGeer A, Perl TM, Price CS, Al Rabeeah AA, Cummings DA Alabdullatif ZN, Assad M, Almulhim A, Makhdoom H, et al. Hospital outbreak of Middle East respiratory syndrome coronavirus. N Engl J Med. 2013;369:407-16

5. Misra DP, Agarwal V, Gasparyan AY, Zimba O. Rheumatologists' perspective on coronavirus disease 19 (COVID-19) and potential therapeutic targets. Clin Rheumatol. 2020;39(7):2055-62.

6. COVID-19 Situation report 68 by the World Health Organization. https:// www.who.int/docs/default-source/coronaviruse/situationreports/20200 328-sitrep-68-covid-19.pdf?sfvrsn =384bc74c 2.2 .

7. Guan W-J, Ni Z-Y, Hu Y, et al. Clinical characteristics of coronavirus disease 2019 in China. N Engl J Med. 2020;382(18):1708-20.

8. Vaira LA, Salzano G, Fois AG, Piombino P, De Riu G. Potential pathogenesis of ageusia and anosmia in COVID-19 patients. Int Forum Allergy Rhinol. 2020;10(9):1103-4.

9. Kakodkar P, Kaka N, Baig MN. A comprehensive literature review on the clinical presentation, and management of the pandemic coronavirus disease 2019 (COVID-19). Cureus. 2020;12(4):e7560.

10. Huang C, Wang Y, Li X, et al. Clinical features of patients infected with 2019 novel coronavirus in Wuhan, China. Lancet. 2020;395:497-506.

11. Ai T, Yang Z, Hou H, et al. Correlation of chest CT and RT-PCR testing in Coronavirus Disease 2019 (COVID-19) in China: a report of 1014 cases. Radiology. 2020;296(2):E32-40. 
12. Li G, Chen X, Xu A. Profile of specific antibodies to the SARS-associated coronavirus. N Engl J Med. 2003;349(5):508-9.

13. Zhang G, Nie S, Zhang Z, Zhang Z. Longitudinal change of SARS-Cov2 antibodies in patients with COVID-19. J Infect Dis. 2020;222(2):183-8.

14. Porfidia A, Pola R. Venous thromboembolism in COVID-19 patients. J Thromb Haemost. 2020;18(6):1516-7.

15. Liu J, Cao R, Xu M, et al. Hydroxychloroquine, a less toxic derivative of chloroquine, is effective in inhibiting SARS-CoV-2 infection in vitro. Cell Discov. 2020;6:16

16. Chen Z, Hu J, Zhang Z, et al. Efficacy of hydroxychloroquine in patients with COVID-19: results of a randomized clinical trial. medRxiv 2020 (in press).

17. Wang $M$, Cao $R$, Zhang $L$, et al. Remdesivir and chloroquine effectively inhibit the recently emerged novel coronavirus (2019-nCoV) in vitro. Cell Res. 2020;30(3):269-71.

18. Cortegiani A, Ingoglia G, Ippolito M, Giarratano A, Einav S. A systematic review on the efficacy and safety of chloroquine for the treatment of COVID-19. J Crit Care. 2020;57:279-83.

19. Pavel MA, Petersen EN, Wang H, Lerner RA, Hansen SB. Studies on the mechanism of general anesthesia. Proc Natl Acad Sci USA. 2020;117:13757-66.

20. Yuan Z, Pavel MA, Wang H, Hansen SB. Hydroxychloroquine: mechanism of action inhibiting SARS-CoV2 entry. bioRxiv 2020 (in press).

21. Procacci P, Macchiagodena M, Pagliai M, Guarnieri G, lannone F. Interaction of hydroxychloroquine with SARS-CoV2 functional proteins using allatoms non-equilibrium alchemical simulations. Chem Commun (Camb). 2020:56(62):8854-6.

22. Allegra A, Tonacci A, Pioggia G, Musolino C, Gangemi S. Vitamin deficiency as risk factor for SARS-CoV-2 infection: correlation with susceptibility and prognosis. Eur Rev Med Pharmacol Sci. 2020;24(18):9721-38.

23. Kast II, McFarlane AJ, Globinska A, Sokolowska M, Wawrzyniak P, Sanak M, Schwarze J, Akdis CA, Wanke K. Respiratory syncytial virus infection influences tight junction integrity. Clin Exp Immunol. 2017;190:351-9.

24. Chen Y, Leng K, Lu Y, Wen L, Qi Y, Gao W, Chen H, Bai L, An X, Sun B, Wang $P$, Dong J. Epidemiological features and time-series analysis of influenza incidence in urban and rural areas of Shenyang, China, 2010-2018. Epidemiol Infect. 2020;148:e29.

25. Rossi GA, Fanous H, Colin AA. Viral strategies predisposing to respiratory bacterial superinfections. Pediatr Pulmonol. 2020;55:1061-73.

26. Holick MF. Vitamin D deficiency. N Engl J Med. 2007;357:266-81.

27. Pike JW, Christakos S. Biology and Mechanisms of Action of the Vitamin D Hormone. Endocrinol Metab Clin. 2017:46:815-43.

28. Rondanelli M, Miccono A, Lamburghini S, Avanzato I, Riva A, Allegrini P, Faliva MA, Peroni G, Nichetti M, Perna S. Self-Care for Common Colds: The Pivotal Role of Vitamin D, Vitamin C, Zinc, and Echinacea in Three Main Immune Interactive Clusters (Physical Barriers, Innate and Adaptive Immunity) Involved during an Episode of Common Colds-Practical Advice on Dosages and on the Time to Take These Nutrients/Botanicals in order to Prevent or Treat Common Colds. Evid Based Complement Alternat Med. 2018;2018:5813095.

29. Schwalfenberg GK. A review of the critical role of vitamin $D$ in the functioning of the immune system and the clinical implications of vitamin D deficiency. Mol Nutr Food Res. 2011:55:96-108.

30. Liu PT, Stenger S, Li H, Wenzel L, Tan BH, Krutzik SR, Ochoa MT, Schauber J, Wu K, Meinken C, et al. Toll-like receptor triggering of a vitamin D-mediated human antimicrobial respons. Science. 2006;311:1770-3.

31. Adams JS, Ren S, Liu PT, Chun RF, Lagishetty V, Gombart AF, Borregaard $\mathrm{N}$, Modlin RL, Hewison M. Vitamin d-directed rheostatic regulation of monocyte antibacterial responses. J Immunol. 2009;182:4289-95.

32. Laaksi I. Vitamin D and respiratory infection in adults. Proc Nutr Soc. 2012;71:90-7.

33. Herr C, Shaykhiev R, Bals R. The role of cathelicidin and defensins in pulmonary inflammatory diseases. Expert Opin Biol Ther. 2007;7:1449-61.

34. Greiller CL, Martineau AR. Modulation of the immune response to respiratory viruses by vitamin D. Nutrients. 2015;7:4240-70.

35. Yuk JM, Shin DM, Lee HM, Yang CS, Jin HS, Kim KK, Lee ZW, Lee SH, Kim JM, Jo EK. Vitamin D3 induces autophagy in human monocytes/macrophages via cathelicidin. Cell Host Microbe. 2009;6:231-43.

36. Wang TT, Nestel FP, Bourdeau V, et al. Cutting edge: 1,25-dihydroxyvitamin D3 is a direct inducer of antimicrobial peptide gene expression. J Immunol. 2004;173:2909-12.
37. Huang C, Wang Y, Li X, Ren L, Zhao J, Hu Y, Zhang L, Fan G, Xu J, Gu X, et al. Clinical features of patients infected with 2019 novel coronavirus in Wuhan, China. Lancet. 2020;395(10223):497-506.

38. Sharifi A, Vahedi H, Nedjat S, Rafiei H, Hosseinzadeh-Attar MJ. Effect of single-dose injection of vitamin D on immune cytokines in ulcerative colitis patients: a randomized placebo-controlled trial. APMIS. 2019;127:681-7.

39. Gombart AF, Pierre A, Maggini S. A review of micronutrients and the immune system-working in harmony to reduce the risk of infection. Nutrients. 2020;12:236.

40. Cantorna MT, Snyder L, Lin YD, Yang L. Vitamin D and 1,25(OH)2D regulation of T cells. Nutrients. 2015;7:3011-21.

41. Jeffery LE, Burke F, Mura M, Zheng Y, Qureshi OS, Hewison M, Walker LS, Lammas DA, Raza K, Sansom DM. 1,25-Dihydroxyvitamin D3 and IL-2 combine to inhibit T cell production of inflammatory cytokines and promote development of regulatory T cells expressing CTLA-4 and FoxP3. J Immunol. 2009;183:5458-67.

42. Murdaca G, Tonacci A, Negrini S, Greco M, Borro M, Puppo F, Gangemi S. Emerging role of vitamin D in autoimmune diseases: an update on evidence and therapeutic implications. Autoimmun Rev. 2019;18(9):102350.

43. Vasarhelyi B, Satori A, Olajos F, Szabo A, Beko G. Low vitamin D levels among patients at Semmelweis University: retrospective analysis during a one-year period. Orv Hetil. 2011;152:1272-7.

44. MacLaughlin J, Holick MF. Aging decreases the capacity of human skin to produce vitamin D3. J Clin Invest. 1985;76:1536-8.

45. Grober U, Kisters K. Influence of drugs on vitamin D and calcium metabolism. Dermatoendocrinol. 2012;4:158-66.

46. Lei GS, Zhang C, Cheng BH, Lee CH. Mechanisms of action of vitamin $\mathrm{d}$ as supplemental therapy for pneumocystis pneumonia. Antimicrob Agents Chemother. 2017;61:1.

47. Mousavi S, Bereswill S, Heimesaat MM. Immunomodulatory and antimicrobial effects of vitamin C. Eur J Microbiol Immunol. 2019;9:73-9.

48. Colunga-Biancatelli RML, Berrill M, Marik PE. The antiviral properties of vitamin C. Expert Rev Anti Infect Ther. 2020;18:99-101.

49. Urashima M, Segawa T, Okazaki M, Kurihara M, Wada Y, Ida H. Randomized trial of vitamin D supplementation to prevent seasonal influenza A in schoolchildren. Am J Clin Nutr. 2010;91:1255-60.

50. Zhou J, Du J, Huang L, Wang Y, Shi Y, Lin H. Preventive effects of vitamin d on seasonal influenza a in infants: a multicenter, randomized, open, controlled clinical trial. Pediatr Infect Dis J. 2018;37:749-54.

51. Urashima M, Mezawa H, Noya M, Camargo CA Jr. Effects of vitamin D supplements on influenza A illness during the 2009 H1N1 pandemic: a randomized controlled trial. Food Funct. 2014;5:2365-70.

52. Arihiro S, Nakashima A, Matsuoka M, Suto S, Uchiyama K, Kato T, Mitobe J, Komoike N, Itagaki M, Miyakawa Y, et al. Randomized trial of vitamin d supplementation to prevent seasonal influenza and upper respiratory infection in patients with inflammatory bowel disease. Inflamm Bowel Dis. 2019;25:1088-95.

53. Loeb M, Dang AD, Thiem VD, Thanabalan V, Wang B, Nguyen NB, Tran HTM, Luong TM, Singh P, Smieja M, et al. Effect of Vitamin D supplementation to reduce respiratory infections in children and adolescents in Vietnam: A randomized controlled trial. Influenza Other Respir Viruses. 2019;13:176-83.

54. Gruber-Bzura BM. Vitamin D and Influenza-Prevention or Therapy? Int J Mol Sci. 2018;19:2419.

55. Mansueto P, Seidita A, Vitale G, Gangemi S, laria C, Cascio A. Vitamin D deficiency in hiv infection: not only a bone disorder. Biomed Res Int. 2015;2015:735615.

56. Grant WB, Al Anouti F, Moukayed M. Targeted 25-hydroxyvitamin D concentration measurements and vitamin D3 supplementation can have important patient and public health benefits. Eur J Clin Nutr. 2020;74:366-76.

57. Norman K, Pichard C, Lochs H, Pirlich M. Prognostic impact of diseaserelated malnutrition. Clin Nutr. 2008;27(1):5-15.

58. Caccialanza R, Laviano A, Lobascio F, Montagna E, Bruno R, Ludovisi S, Corsico AG, Di Sabatino A, Belliato M, Calvi M, lacona I, Grugnetti G, Bonadeo E, Muzzi A, Cereda E. Early nutritional supplementation in noncritically ill patients hospitalized for the 2019 novel coronavirus disease (COVID-19): Rationale and feasibility of a shared pragmatic protocol. Nutrition. 2020;74:110835. 
59. Tian Y, Rong L, Nian W, He Y. Review article: gastrointestinal features in COVID-19 and the possibility of faecal transmission. Aliment Pharmacol Ther. 2020:51:843-51.

60. Panarese A, Pesce F, Porcelli P, et al. Chronic functional constipation is strongly linked to vitamin D deficiency. World J Gastroenterol. 2019;25:1729-40.

61. Kong J, Zhu X, Shi Y, et al. VDR attenuates acute lung injury by blocking Ang-2-Tie-2 pathway and renin-angiotensin system. Mol Endocrinol. 2013:27:2116-25.

62. Malek MA. A brief review of interplay between vitamin D and angiotensin-converting enzyme 2: Implications for a potential treatment for COVID-19. Rev Med Virol. 2020;30(5):e2119.

63. Iddir M, Brito A, Dingeo G, et al. Strengthening the Immune System and Reducing Inflammation and Oxidative Stress through Diet and Nutrition: Considerations during the COVID-19 Crisis. Nutrients. 2020;12(6):E1562.

64. Panarese A, Shahini E. Letter: Covid-19, and vitamin D. Aliment Pharmaco Ther. 2020;51(10):993-5.

65. Marik PE, Kory P, Varon J. Does vitamin D status impact mortality from SARS-CoV-2 infection? Med Drug Discov. 2020;6:1-2.

66. Shi Y, Liu T, Yao LI, et al. Chronic vitamin D deficiency induces lung fibrosis through activation of the renin-angiotensin system. Sci Rep. 2017;7:3312.

67. Tsujino I, Ushikoshi-Nakayama R, Yamazakj T, et al. Pulmonary activation of vitamin D3 and preventive effect against interstitial pneumonia. J Clin Biochem Nutr. 2019;65:245-51.

68. Martineau AR, Jolliffe DA, Hooper RL, et al. Vitamin D supplementation to prevent acute respiratory tract infections: systematic review and metaanalysis of individual participant data. BMJ. 2017:356:i6583.

69. Alvarez N, Aguilar-Jimenez W, Rugeles MT. The potential protective role of vitamin D supplementation on HIV-1 infection. Front Immunol. 2019;10:2291

70. Hanff TC, Harhay MO, Brown TS, Cohen JB, Mohareb AM. Is there an association between COVID-19 mortality and the renin-angiotensin system a call for epidemiologic investigations. Clin Infect Dis. 2020;71(15):870-4.

71. Mohammad S, Mishra A, Ashraf MZ. Emerging role of vitamin D and its associated molecules in pathways related to pathogenesis of thrombosis. Biomolecules. 2019;9(11):649.

72. Entrenas Castillo M, Entrenas Costa LM, Vaquero Barrios JM, Alcalá Díaz JF, López Miranda J, Bouillon R, Quesada Gomez JM. Effect of calcifediol treatment and best available therapy versus best available therapy on intensive care unit admission and mortality among patients hospitalized for COVID-19: A pilot randomized clinical study. J Steroid Biochem Mol Biol. 2020:203:105751.

73. Su W, Chen Y, Wang C, Ding X, Rwibasira G, Kong Y. Human cathelicidin LL-37 inhibits platelet aggregation and thrombosis via Src/PI3K/Akt signaling. Biochem Biophys Res Commun. 2016;473(1):283-9.

74. Zhang J, McCullough PA, Tecson KM. Vitamin D deficiency in association with endothelial dysfunction: Implications for patients with COVID-19. Rev Cardiovasc Med. 2020;21(3):339-44.

75. Tian Y, Rong L. Letter: Covid-19, and vitamin D Authors'reply. Aliment Pharmacol Ther. 2020;51(10):995-6.
76. Weir EK, Thenappan T, Bhargava M, Chen Y. Does vitamin D deficiency increase the severity of COVID-19? Clin Med (Lond). 2020;20(4):e107-8.

77. Rhodes JM, Subramanian S, Laird E, Kenny RA. Editorial: low population mortality from COVID-19 in countries south of latitude 35 degrees North supports vitamin $\mathrm{D}$ as a factor determining severity. Aliment Pharmacol Ther. 2020;51(12):1434-7.

78. Jakovac H. COVID-19 and vitamin D-Is there a link and an opportunity for intervention? Am J Physiol Endocrinol Metab. 2020;318(5):E589.

79. Andersen CJ, Murphy KE, Fernandez ML. Impact of obesity and metabolic syndrome on immunity. Adv Nutr. 2016;7:66-75.

80. Dhama K, Sharun K, Tiwari R, Dadar M, Malik YS, Singh KP, et al. COVID-19, an emerging coronavirus infection: advances and prospects in designing and developing vaccines, immunotherapeutics, and therapeutics. Hum Vaccin Immunother. 2020;16(6):1232-8.

81. Carter SJ, Baranauskas MN, Fly AD. Considerations for obesity, vitamin D, and physical activity amidst the COVID-19 pandemic. Obesity (Silver Spring). 2020

82. Cooper ID, Crofts CAP, DiNicolantonio JJ, Malhotra A, Elliott B, Kyriakidou Y, Brookler KH. Relationships between hyperinsulinaemia, magnesium, vitamin D, thrombosis and COVID-19: rationale for clinical management. Open Heart. 2020;7(2):e001356.

83. La Vignera S, Cannarella R, Condorelli RA, Torre F, Aversa A, Calogero AE. Sex-specific SARS-CoV-2 mortality: among hormone-modulated ACE2 expression, risk of venous thromboembolism and hypovitaminosis D. Int J Mol Sci. 2020;21(8):2948.

84. Walker RF, Zakai NA, MacLehose RF, Cowan LT, Adam TJ, Alonso A, Lutsey $\mathrm{PL}$. Association of testosterone therapy with risk of venous thromboembolism among men with and without hypogonadism. JAMA Intern Med. 2020;180(2):190-7.

85. Harman SM, Metter EJ, Tobin JD, et al. Longitudinal effects of aging on serum total and free testosterone levels in healthy men. Baltimore Longitudinal Study of Aging. J Clin Endocrinol Metab. 2001;86:724-31.

86. Salciccia S, Del Giudice F, Gentile V, Mastroianni CM, Pasculli P, Di Lascio G, Ciardi MR, Sperduti I, Maggi M, De Berardinis E, Eisenberg ML, Sciarra A. Interplay between male testosterone levels and the risk for subsequent invasive respiratory assistance among COVID-19 patients at hospital admission. Endocrine. 2020;70(2):206-10.

87. Liu Q, Zhou YH, Yang ZQ. The cytokine storm of severe influenza and development of immunomodulatory therapy. Cell Mol Immunol. 2016;13(1):3-10.

88. Labudzynskyi D, Shymanskyy I, Veliky M. Role of vitamin D3 in regulation of interleukin-6 and osteopontin expression in liver of diabetic mice. Eur Rev Med Pharmacol Sci. 2016;20(13):2916-9.

\section{Publisher's Note}

Springer Nature remains neutral with regard to jurisdictional claims in published maps and institutional affiliations.

Ready to submit your research? Choose BMC and benefit from

- fast, convenient online submission

- thorough peer review by experienced researchers in your field

- rapid publication on acceptance

- support for research data, including large and complex data types

- gold Open Access which fosters wider collaboration and increased citations

- maximum visibility for your research: over 100M website views per year

At BMC, research is always in progress.

Learn more biomedcentral.com/submissions 